\title{
Molecular Identification of Diphyllobothrium latum from a Pediatric Case in Taiwan
}

\author{
Yu-Chin An', Chia-Cheng Sung ${ }^{2}$, Chih-Chien Wang'2, Hsin-Chung Lin ${ }^{3}$, Kuang-Yao Chen ${ }^{4}$, Fu-Man Ku \\ Ruei-Min Chen ${ }^{3}$, Mei-Li Chen ${ }^{3}$, Kuo-Yang Huang ${ }^{6, *}$ \\ ${ }^{1}$ Department of Emergency Medicine, Tri-Service General Hospital, National Defense Medical Center, Taipei, Taiwan; ${ }^{2}$ Departments of Pediatrics, \\ Tri-Service General Hospital, National Defense Medical Center, Taiwan; ${ }^{3}$ Division of Clinical Pathology, Department of Pathology, Tri-Service General \\ Hospital, National Defense Medical Center, Taipei, Taiwan; ${ }^{2}$ Department of Parasitology, College of Medicine, Chang Gung University, Taoyuan, \\ Taiwan; ${ }^{5}$ Molecular Regulation and Bioinformatics Laboratory, Department of Parasitology, College of Medicine, Chang Gung University, Taoyuan, \\ Taiwan; ${ }^{6}$ Graduate Institute of Pathology and Parasitology, National Defense Medical Center, Taipei, Taiwan
}

\begin{abstract}
Human diphyllobothriasis is a parasitic disease caused by ingestion of larvae (plerocercoids) in raw or undercooked fish and commonly found in temperate areas. Rare cases were reported in tropical or subtropical areas especially in children. The first documented case of pediatric diphyllobothriasis in Taiwan had been reported 11 years ago. Here, we report another 8-year-old girl case who presented with a live noodle-like worm hanging down from her anus, with no other detectable symptoms. We pulled the worm out and found the strobila being $260 \mathrm{~cm}$ in length. Examination of gravid proglottids showed that they were wider than their lengths, containing an ovoid cirrus sac in the anterior side and the rosette-shaped uterus. Eggs extracted from the uterus were ovoid and operculated. Diphyllobothrium latum was confirmed by molecular analysis of the mitochondrial DNA cytochrome $c$ oxidase subunit 1 (cox1) gene. The girl was treated with a single oral dose of praziquantel, and no eggs or proglottids were observed from her stool in the subsequent 3 months. The reemergence of human diphyllobothriasis in non-endemic countries is probably due to prevalent habit of eating imported raw fish from endemic areas. This pediatric case raised our concern that human diphyllobothriasis is likely underestimated because of unremarkable symptoms.
\end{abstract}

Key words: Diphyllobothrium latum, diphyllobothriasis, pediatric case, cox1

\section{INTRODUCTION}

Tapeworms of the genus Diphyllobothrium, known as "fish tapeworms" or "broad tapeworms", are worldwide in distribution and commonly found in temperate freshwater ecosystems. Infections of Diphyllobothrium spp. (diphyllobothriasis) are mostly reported in Western Europe, North America, South America, and the Far East, including Korea, Japan, and Russia $[1,2]$. Rare cases were reported in tropical or subtropical countries where these cases may be related to imported fish from endemic areas [2]. The most prevalent human diphyllobothriasis are caused by D. latum, D. dendriticum, D. nihonkaiense, and D. pacificum. The life cycles of these species are complex,

\footnotetext{
- Received 11 June 2017, revised 27 June 2017, accepted 2 July 2017.

*Corresponding author (cguhgy6934@gmail.com)

(C) 2017, Korean Society for Parasitology and Tropical Medicine

This is an Open Access article distributed under the terms of the Creative Commons Attribution Non-Commercial License (http://creativecommons.org/licenses/by-nc/4.0) which permits unrestricted non-commercial use, distribution, and reproduction in any medium, provided the original work is properly cited.
}

comprising of 2 intermediate hosts (a copepod and a fish) and a definitive host (humans or other piscivorous mammals).

Human diphyllobothriasis takes place through the ingestion of larvae (plerocercoids) in raw or undercooked fish. In recent years, eating raw fish becomes popular in Taiwan, resulting in the demand for imported fish. This may also increase the risk of Diphyllobothrium infection due to eating imported fish. Since Taiwan is not in an endemic area, rare cases were previously reported, especially for pediatric cases. The first published pediatric case of $D$. latum infection in Taiwan had been reported 11 years ago [3]. Here, we present another rare case of $D$. latum infection in an 8-year-old girl, which was confrimed by molecular analysis of the mitochondrial DNA cytochrome $c$ oxidase subunit 1 ( $\operatorname{cox} 1)$ gene.

\section{CASE REPORT}

An 8-year-old Taiwanese girl who was $127 \mathrm{~cm}$ tall and weighed $24 \mathrm{~kg}$ presented without discomfort, but a live noo- 
A

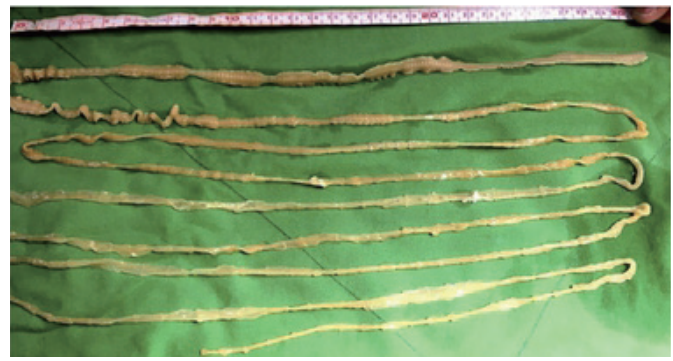

C

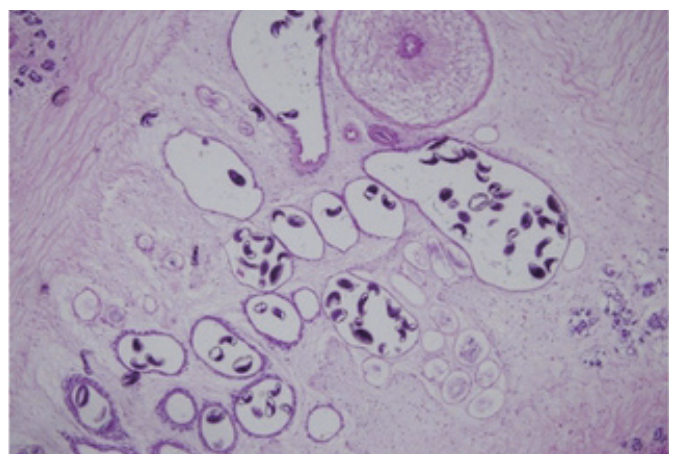

B

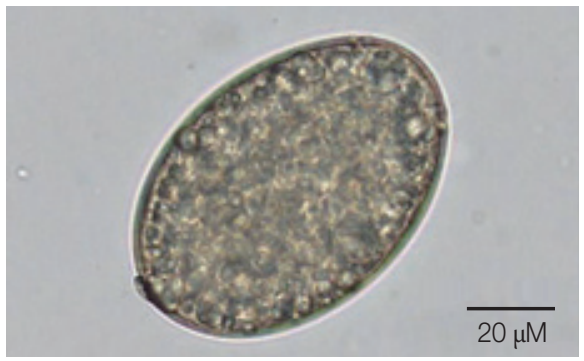

D

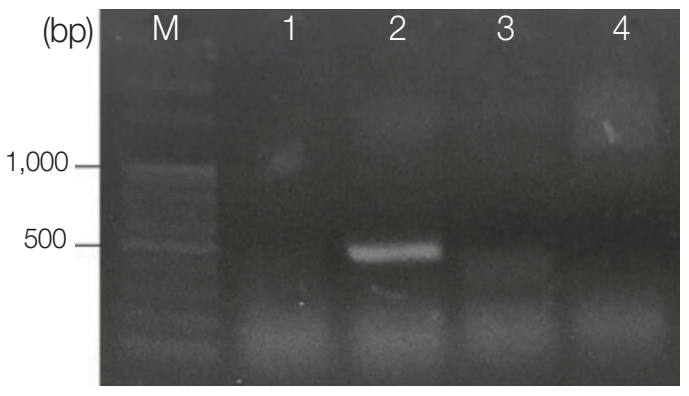

Fig. 1. (A) A strobila of Diphyllobothrium latum expelled by the patient (about $260 \mathrm{~cm}$ ). (B) An egg extracted from the uterus of a gravid proglottid. The egg was ovoid and operculated. (C) Tissue section stained with hematoxylin and eosin showing the rosette-shaped uterus of a gravid proglottid. An ovoid cirrus sac is located in the anterior side of the gravid proglottid. Several eggs are observed in the loops of the uterus. (D) Molecular identification of $D$. latum by PCR. Lanes (1-4) represent the PCR products amplified by using different primers for the most common Diphyllobothrium species. Lane 1, D. pacificum; lane 2, D. latum; lane 3, D. dendriticum; lane 4, D. nihonkaiense. M: marker.

dle-like worm hanging down from her anus which was discovered after defecation. She was a healthy elementary school student, lived in a well-off family and loved to eat raw fish without any history of travel to a foreign country. Initially we pulled the worm out and found a strobila of about $260 \mathrm{~cm}$ in length (Fig. 1A). The worm was still alive and movable while we put it on the towel.

Physical examinations showed no specific signs, such as pale conjunctiva or abdominal tenderness. The laboratory data revealed the hemoglobin count to be $12.3 \mathrm{~g} / \mathrm{dl}$, the red blood cell count to be $4.51 \times 10^{6} / \mu \mathrm{l}$, and the mean corpuscular volume (MCV) of $79.8 \mathrm{fl}$. Platelet count was $248 \times 10^{3} / \mu \mathrm{l}$, and the white blood cell count was $5.07 \times 10^{3} / \mu l$ (neutrophils $51.1 \%$; lymphocytes $40.2 \%$; eosinophils $3.2 \%$ ).

Diphyllobothriasis was diagnosed by examination of the gravid proglottids and eggs. The segments are wider than their lengths, which contain an ovoid cirrus sac in the anterior side of each proglottid. The rosette-shaped gravid uterus has 5-6 loops on each side (Fig. 1B). Eggs extracted from the worm's uterus were found to be ovoid, yellow-brown, and operculated (Fig. 1C). The specific identification of Diphyllobothrium species is very difficult only by morphological observations. Hence,
Table 1. Primers used for PCR in this study

\begin{tabular}{|c|c|c|}
\hline Specificity & Strand & Sequence $\left(5^{\prime}>3^{\prime}\right)$ \\
\hline Common & Reverse & ATGATAAGGGAYAGGRGCYCA \\
\hline $\begin{array}{l}\text { Diphyllobothrium } \\
\text { latum }\end{array}$ & Forward & GGGGTGTTACGGGTATTATACTC \\
\hline D. dendriticum & Forward & GTGTIITCATITGATGATGACCAGTO \\
\hline D. pacificum & Forward & ACATGTGTGTAGTAACCTTGGC \\
\hline D. nihonkaiense & Forward & CTTGTTGTCTGGCCTTCCT \\
\hline
\end{tabular}

molecular analysis using PCR (Table. 1) is the only reliable approach to differentiate these parasites. Amplification of the mitochondrial DNA cox1 gene was performed as previously described [4] (Fig. 1D). The expected product sizes were 437 bp for D. latum, 318 bp for D. dendriticum, 727 bp for D. pacificum, and 1,232 bp for D. nihonkaiense. DNA extracted from the tapeworm sample was successfully amplified for $D$. latum, yielding a specific product size close to the expected one, and no products were amplified for the other Diphyllobothrium species. The data confirmed that the species of Diphyllobothrium is D. latum.

The girl was treated with a single oral dose of praziquantel ( $8.5 \mathrm{mg} / \mathrm{kg} /$ dose). After administration, no eggs or proglottids were observed from the stool in the subsequent 3 months. Ra- 
diological examinations or gastrointestinal fiberoptic endoscopy were not performed due to her young age and no other remarkable symptoms.

\section{DISCUSSION}

There are several species of Diphyllobothrium infecting humans. Among these, D. latum, D. dendriticum, D. pacificum, and $D$. nihonkaiense have been shown to be the main species. D. latum was commonly reported all over the world, including Europe, North America (Alaska, Great Lakes), and Asia [2,5]. D. pacificum was found in the Pacific Coast of South America and Japan. D. nihonkaiense is prevalent in Japan and Korea, but rare in Europe or America. In Taiwan, only rare cases of diphyllobothriasis were reported in the past caused by D. latum and presumably related to imported salmon $[3,6]$. Recent taxonomic studies indicated that the majority of human diphyllobothriasis was caused by $D$. nihonkaiense. Many cases of $D$. latum infection reported in Korea were re-identified as D. nihonkaiense based on molecular analysis of the mitochondrial cox1 gene [7]. Therefore, it was necessary to perform molecular analysis in order to identify the species of Diphyllobothrium. In our study, we successfully identified the broad tapeworm to the species level by PCR analysis of cox1 gene. We used formalin- and ethanol-preserved samples for extraction of DNA and subsequent PCR analysis. However, DNA can be extracted only from ethanol-preserved samples but only with difficulty from formalin-preserved ones. This observation is consistent with the results of previous studies, indicating that formalin irreversibly affects the quality of DNA.

Since D. latum was identified, we sought to investigate the possible source of this parasitic infection. In previous studies, including rare cases reported in subtropical and tropical Asia $[1,2,5], D$. latum is worldwide in distribution but D. nihonkaiense seems to dominate in the northern Pacific region. The second intermediate hosts of $D$. latum, including freshwater, anadromous, and marine fish had been reported, and the pacific salmon was the major host which contributed to $D$. nihonkaiense infection $[2,7]$. More species of second intermediate hosts infected with $D$. latum possibly result in wider distribution, especially in non-endemic areas, due to imported fish. However, the reliable cause of $D$. latum infection in Taiwan instead of D. nihonkaiense or other Diphyllobothrium spp. infection was still unclear. The different environmental adaptability of Diphyllobothrium spp. is worthy of investigation. In our case, the girl had never ingested salmon. Thus, her diphyllobothriasis was presumably caused by ingestion of other species of imported fish, although it is hard to trace the specific source.

D. latum infections are mostly asymptomatic, but some patients may present with transient abdominal discomfort, abdominal pain, diarrhea, fatigue, and less commonly intestinal obstruction. Severe cases of $D$. latum infection may lead to megaloblastic anemia because vitamin $\mathrm{B}_{12}$ is absorbed by the worm. Lee et al. [8] showed 5 cases of D. latum infection among children in Korea, and 3 of them presented with abdominal pain, 1 with anemia, and 1 with passage of proglottids [8]. The first pediatric case in Taiwan, a 8-year-old boy, also presented with passage of proglottids [3]. In our case, the tapeworm was initially misidentified as a part of intestine and finally recognized as $D$. latum. Due to the unremarkable symptoms and chief complaints of our case, we propose that $D$. latum infection may be underestimated in Taiwan.

Praziquantel is the first choice of treatment for diphyllobothriasis. Oral administration of a single dose from 10 to 25 $\mathrm{mg} / \mathrm{kg}$ has been recommended to treat $D$. latum infection. Almost all reported cases have been effectively cured with rare side effects. In our case, the proglottids were expelled before a single dose of praziquantel treatment $(8.5 \mathrm{mg} / \mathrm{kg} /$ dose $)$, and no eggs or proglottids were observed in the stool during follow-up. Intraduodenal gastrografin has been reported to be an effective treatment as an alternative therapy for diphyllobothriasis. However, this method is limited for choice because insertion of duodenal tube is painful, which is not suitable for children.

We examined the level of hemoglobin and the stool in the subsequent 3 months for follow-up. All of them showed negative results. We did not check the level of vitamin $B_{12}$ because the levels of hemoglobin and MCV were normal, and no evidence of anemia was found. In previous reports, gastrointestinal fiberoptic endoscopy and abdominal magnetic resonance imaging were used for diagnosis and removal of the residual scolex $[2,8]$. However, these examinations are costly and difficult to be accepted for children.

Since eating raw fish imported from the endemic area becomes more popular, prevention of diphyllobothriasis should be taken seriously. Deep-frozen fish (at $-10^{\circ} \mathrm{C}$ for $24-48 \mathrm{hr}$ ) or brine-treated fish $(12 \% \mathrm{NaCl})$ is safe for consumption [6]. Additionally, plerocercoid larvae could be killed at a temperature of $55^{\circ} \mathrm{C}$ in 5 min [5]. Hence, it is not recommended to eat raw or smoked fish and consumption of well-cooked fish is the 
better way to prevent the reemergence of diphyllobothriasis.

In conclusion, we should be aware of reemergence of human diphyllobothriasis in non-endemic countries due to prevalent habit of eating raw fish that may be imported from endemic areas. Additionally, it is noteworthy that human diphyllobothriasis is likely underestimated because of unremarkable symptoms.

\section{ACKNOWLEDGMENT}

This work was funded by the Ministry of Science and Technology, Republic of China (MOST 105-2320-B-016 -019 -MY2) to Kuo-Yang Huang.

\section{CONFLICT OF INTEREST}

All authors declare no conflict of interest.

\section{REFERENCES}

1. Kuchta R, Brabec J, Kubackova P, Scholz T. Tapeworm Diphyllobothrium dendriticum (Cestoda)--neglected or emerging human parasite? PLoS Negl Trop Dis 2013; 7: e2535.

2. Scholz T, Garcia HH, Kuchta R, Wicht B. Update on the human broad tapeworm (genus diphyllobothrium), including clinical rel- evance. Clin Microbiol Rev 2009; 22: 146-160.

3. Chou HF, Yen CM, Liang WC, Jong YJ. Diphyllobothriasis latum: the first child case report in Taiwan. Kaohsiung J Med Sci 2006; 22: 346-351.

4. Wicht B, Yanagida T, Scholz T, Ito A, Jimenez JA, Brabec J. Multiplex PCR for differential identification of broad tapeworms (Cestoda: Diphyllobothrium) infecting humans. J Clin Microbiol 2010; 48: 3111-3116.

5. Dick TA, Nelson PA, Choudhury A. Diphyllobothriasis: update on human cases, foci, patterns and sources of human infections and future considerations. Southeast Asian J Trop Med Public Health 2001; 32 (suppl): 59-76.

6. Lou HY, Tsai PC, Chang CC, Lin YH, Liao CW, Kao TC, Lin HC, Lee WC, Fan CK. A case of human diphyllobothriasis in northern Taiwan after eating raw fish fillets. J Microbiol Immunol Infect 2007; 40: 452-456.

7. Park SH, Jeon HK, Kim JB. Four additional cases of Diphyllobothrium nihonkaiense infection confirmed by analysis of COX1 gene in Korea. Korean J Parasitol 2015; 53: 105-108.

8. Kim HJ, Eom KS, Seo M. Three cases of Diphyllobothrium nihonkaiense infection in Korea. Korean J Parasitol 2014; 52: 673676.

9. Lee SH, Park H, Yu ST. Diphyllobothrium latum infection in a child with recurrent abdominal pain. Korean J Pediatr 2015; 58: 451-453.

10. Raether W, Hänel H. Epidemiology, clinical manifestations and diagnosis of zoonotic cestode infections: an update. Parasitol Res 2003; 91: 412-438. 